\title{
A “20/20” Match: ACC/AHA 2017 versus ESC/ESH 2018 Guidelines for Management of Hypertension
}

\author{
Akshyaya Pradhan, DM, FAPSIC, FACC, FICA, FAPSIC ${ }^{10}$ Shweta Vohra, MD ${ }^{10}$ \\ Rishi Sethi, DM, FACC, FESC, FSCAI, FAPSIC, FRCP ${ }^{1}$ \\ ${ }^{1}$ Department of Cardiology, King George's Medical University, \\ Lucknow, Uttar Pradesh, India \\ Address for correspondence Rishi Sethi, DM, FACC, FESC, FSCAI, \\ FAPSIC, FRCP, Department of Cardiology, King George's Medical \\ University, Lucknow, Uttar Pradesh, 226003, India \\ Int J Angiol 2021;30:243-248. \\ (e-mail: drrishisethi1@gmail.com).
}

\begin{abstract}
Keywords

- blood pressure targets

- risk score

- cardiovascular disease

- prevention

- combination therapy

Hypertension, the commonest noncommunicable disease globally, is an important risk factor for cardiovascular disease and renal failure. Theoretically, while it is easy to diagnose and manage by simple measures, practically it has been observed that not only treatment but also diagnosis and its preventive measures are inadequate in developing as well as developed nations. Several guidelines by various international organizations are available to guide clinicians for hypertension management. Though the basic principles of hypertension management are similar in all the guidelines, subtle differences are there. In this article, we compare the two most widely accepted guidelines for hypertension, that is, American College of Cardiology/American Heart Association 2017 Hypertension Guidelines and 2018 European Society of Cardiology and European Society of Hypertension Guidelines on Hypertension. Both the differences and similarities between these two widely followed guidelines are presented.
\end{abstract}

Hypertension (HTN) is the most common cardiovascular disorder globally. Blood pressure (BP) lowering by antihypertensive therapy has been convincingly demonstrated to lower incidence of stroke (35-40\%), myocardial infarction (20-25\%), and heart failure (50\%). ${ }^{1}$ But, not only treatment but also diagnosis and its preventive measures are inadequate in developing as well as developed nations alike. ${ }^{2}$

Several guidelines by various international organizations are in vogue for HTN treatment. The most recent American College of Cardiology and American Heart Association (ACC/AHA) HTN guidelines were published in Journal of the American College of Cardiology in 2017, while the joint European Society of Cardiology and European Society of Hypertension (ESC/ESH) guidelines for the management of arterial HTN were published in European Heart Journal in late 2018. ${ }^{3,4}$ In an attempt to simplify these guidelines, many authors have put an effort to compile the basic concepts and important areas to be focused upon, to make these guidelines more useful in day-to-day clinical practice. ${ }^{5,6}$ In this article, we compare these two most widely accepted guidelines for HTN, that is, ACC/AHA 2017 Hypertension Guidelines and 2018 ESC/ESH Guidelines on Hypertension head on.

\section{Redefining Hypertension}

The ACC/AHA guidelines define normal BP as $<120 \mathrm{~mm} \mathrm{Hg}$ systolic and $<80 \mathrm{~mm} \mathrm{Hg}$ diastolic. On the contrary, ESC guidelines categorize 120 to $129 \mathrm{~mm} \mathrm{Hg}$ systolic and 80 to $84 \mathrm{~mm} \mathrm{Hg}$ diastolic as normal, while $\mathrm{BP}<120 / 80 \mathrm{~mm} \mathrm{Hg}$ is categorized as "optimal."

In the ACC guidelines, before diagnosing patient as HTN, a new category of "elevated BP" has been added when systolic blood pressure (SBP) is 120 to $129 \mathrm{~mm} \mathrm{Hg}$ and diastolic blood pressure (DBP) $<80 \mathrm{~mm} \mathrm{Hg}$. The ESC guideline has used the terminology "high normal" when SBP is 130 to $139 \mathrm{~mm} \mathrm{Hg}$ and DBP is 85 to $89 \mathrm{~mm} \mathrm{Hg}$ before classifying patient as Grade $1 \mathrm{HTN}$.

The ACC/AHA guidelines redefine HTN as BP $>130 / 80 \mathrm{~mm}$ $\mathrm{Hg}$ and classify HTN into two stages (see - Table 1). On the contrary, the ESC guidelines continue the conventional BP definition of $>140 / 90 \mathrm{~mm} \mathrm{Hg}$ to classify a patient as
(C) 2021. International College of Angiology. All rights reserved. Thieme Medical Publishers, Inc., 333 Seventh Avenue, 18th Floor, New York, NY 10001, USA
DOI https://doi.org/ 10.1055/s-0041-1732433. ISSN 1061-1711. 
Table 1 Definition and classification of hypertension according to both guidelines

\begin{tabular}{|c|c|c|c|c|c|c|}
\hline & \multicolumn{3}{|c|}{ ACC/AHA 2017} & \multicolumn{3}{|c|}{ ESC/ESH 2018} \\
\hline Defining normal BP & \multicolumn{3}{|c|}{$<120 / 80 \mathrm{~mm} \mathrm{Hg}$} & \multicolumn{3}{|c|}{$\begin{array}{l}\text { SBP: } 120-129 \mathrm{~mm} \mathrm{Hg} \\
\text { DBP: } 80-84 \mathrm{mmHg} \\
<120 / 80 \mathrm{~mm} \mathrm{Hg} \text { is "Optimal" }\end{array}$} \\
\hline $\begin{array}{l}\text { Newer terminology before labeling } \\
\text { patient as hypertensive }\end{array}$ & \multicolumn{3}{|c|}{$\begin{array}{l}\text { "Elevated BP" } \\
\text { SBP: } 120-129 \mathrm{~mm} \mathrm{Hg} \\
\text { DBP: }<80 \mathrm{~mm} \mathrm{Hg}\end{array}$} & \multicolumn{3}{|c|}{$\begin{array}{l}\text { "High Normal" } \\
\text { SBP: } 130-139 \mathrm{~mm} \mathrm{Hg} \\
\text { DBP: } 85-89 \mathrm{~mm} \mathrm{Hg}\end{array}$} \\
\hline \multirow[t]{4}{*}{ Classification of hypertension } & & SBP & DBP & & SBP & DBP \\
\hline & Stage 1 & $130-139$ & $80-89$ & Grade 1 & $140-159$ & $90-99$ \\
\hline & \multirow[t]{2}{*}{ Stage 2} & \multirow[t]{2}{*}{$>140$} & \multirow[t]{2}{*}{$>90$} & Grade 2 & $160-179$ & $100-109$ \\
\hline & & & & Grade 3 & $>180$ & $>110$ \\
\hline $\begin{array}{l}\text { Separate classification of isolated } \\
\text { systolic hypertension }\end{array}$ & \multicolumn{3}{|l|}{-} & \multicolumn{3}{|c|}{$\begin{array}{l}\mathrm{SBP}>140 \mathrm{~mm} \mathrm{Hg} \\
\mathrm{DBP}<90 \mathrm{~mm} \mathrm{Hg}\end{array}$} \\
\hline
\end{tabular}

Abbreviations: ACC/AHA, American College of Cardiology/American Heart Association; DBP, diastolic blood pressure; ESC/ESH, European Society of Cardiology/European Society of Hypertension; SBP, systolic blood pressure.

hypertensive and provide three grades of HTN. Additionally, the guidelines have given a separate thought to isolated systolic HTN (SBP > 140, DBP < $90 \mathrm{~mm} \mathrm{Hg}$ ).

Thus, the threshold of labeling patient as hypertensive and classifying him or her in various categories of HTN is higher in ESC than ACC/AHA guideline document.

\section{Method of Measuring BP}

Both guidelines recommend use of auscultatory or oscillometric semiautomatic or automatic sphygmomanometers as the preferred method for measuring BP in the doctor's office.

\section{Office BP, HBPM, and ABPM}

In ESC guidelines, HTN is defined as a persistent elevation in office systolic BP 140 and/or diastolic BP $90 \mathrm{~mm} \mathrm{Hg}$, which is equivalent to a 24 hours ambulatory BP monitoring (ABPM) average of $130 / 80 \mathrm{mmHg}$ or a home BP monitoring (HBPM) average of $135 / 85 \mathrm{mmHg}$.

The ACC/AHA guidelines also advocate use of either form of out-of-office BP measurement. Corresponding to office BP of $130 / 80 \mathrm{~mm} \mathrm{Hg}$, the 24 hours mean ABPM value for diagnosing $\mathrm{HTN}$ is $125 / 75 \mathrm{~mm} \mathrm{Hg}$. HBPM value for diagnosing HTN is similar to day time ABPM value, that is, $130 / 80 \mathrm{~mm} \mathrm{Hg}$ (see - Table 2 ).

\section{Masked HTN and White Coat HTN}

The ACC/AHA guidelines have mentioned screening for white coat HTN in adults with untreated office BP of 130/80 to $160 / 100 \mathrm{~mm} \mathrm{Hg}$, with daytime ABPM or HBPM. The ACC guidelines advocate screening for masked HTN (MH) with HBPM or ABPM in adults with untreated office BP consistently between $120-129 / 75-79 \mathrm{~mm} \mathrm{Hg}$, but presence of target organ damage.

On similar lines, ESC guidelines have put emphasis for diagnosis and management of masked HTN and white coat HTN.

\section{Screening Programs}

The ESC document puts special emphasis on screening of HTN and states that screening programs should be estab-
Table 2 Definitions of hypertension according to office, ambulatory, and home BP levels

\begin{tabular}{|l|l|l|}
\hline Category & ACC/AHA 2017 & ESC 2018 \\
\hline Office BP & $\geq 130 / 80$ & $\geq 140 / 90$ \\
\hline Ambulatory BP & $\geq 130 / 80$ & $\geq 135 / 85$ \\
$\begin{array}{l}\text { - Daytime (or awake) mean } \\
\text { Night-time (or asleep) mean }\end{array}$ & $\geq 110 / 60$ & $\geq 120 / 70$ \\
\hline 24hours mean & $\geq 125 / 75$ & $\geq 130 / 80$ \\
\hline Home BP mean & $\geq 135 / 85$ & $\geq 135 / 85$ \\
\hline
\end{tabular}

Abbreviations: ACC/AHA, American College of Cardiology/American Heart Association; BP, blood pressure; ESC, European Society of Cardiology.

lished to ensure that office BP is measured in all adults, at least every 5 years and more frequently in people with high normal BP.

The ACC/AHA guidelines do not put any such emphasis for screening programs.

Emphasis on Accurate Measurement of Blood Pressure The ACC/AHA guidelines have drawn attention on accurate measurement as well as use of average reading. Strong emphasis has been placed on the use of multiple measurements for deciding BP status of the patient as BP is a continuous variable. Utilizing an average of two or more readings on two or more occasions minimizes the chances of random error.

The ESC guidelines have not put any such focus on multiple measurements or average readings.

\section{Look Out for Secondary Hypertension}

The ACC guidelines mention the importance of considering multiple clinical scenarios that should alert the physician to search for secondary HTN. These include the onset of HTN at early age $<30$ years, uncontrolled or difficult to control HTN, abrupt onset of HTN, worsening BP goals in a previously controlled patients, hypertensive crisis, diastolic HTN in old age, persistent hypokalemia, and mismatch of end organ damage with the severity of HTN.

The ESC guidelines do not mention any such separate consideration for secondary HTN. 


\section{Incorporation of Cardiovascular Risk Assessment in Decision Making}

The ACC/AHA guidelines mention the benefit of using combination approach of treatment by incorporating global cardiovascular disease (CVD) risk assessment in clinical decision making. It recommends the routine use of the ACC/AHA pooled cohort equations to estimate 10 -year risk of atherosclerotic CVD (ASCVD). ${ }^{7}$ For adults with HTN who have an estimated 10year ASCVD risk of at least $10 \%$, the guidelines recommend initiating drug treatment for those with an average BP of $130 / 80 \mathrm{~mm} \mathrm{Hg}$ or higher. For adults with an estimated 10year ASCVD risk less than 10\%, the BP threshold for drug treatment is $140 / 90 \mathrm{~mm} \mathrm{Hg}$ or higher.

While the ACC/AHA guidelines take 10-year ASCVD risk prediction score, ESC guidelines have incorporated SCORE system but do not mention separate BP targets depending on risk score. ${ }^{8}$ The ESC guidelines state that statin therapy should be used more commonly in hypertensive patients with established CVD or moderate-to-high CVD risk according to the SCORE system. Benefit from statin therapy has also been observed in hypertensive patients at the border between low and moderate risk. Antiplatelet therapy, especially low-dose aspirin, is also indicated for secondary prevention in hypertensive patients but is not recommended for primary prevention.

\section{BP Targets}

The ACC/AHA guidelines mention that in hypertensive patients with known CVD or 10 years ASCVD risk $\geq 10 \%$, SBP target $<130 \mathrm{~mm} \mathrm{Hg}$ and DBP target $<80 \mathrm{~mm} \mathrm{Hg}$ are given Class I recommendation. In patients without additional CVD risk, SBP target $<130 \mathrm{~mm} \mathrm{Hg}$ and DBP target $<80 \mathrm{~mm} \mathrm{Hg}$ are given Class IIb recommendation.

The ESC guidelines recommended that the first objective of treatment should be to lower BP to $<140 / 90 \mathrm{~mm} \mathrm{Hg}$ in all patients and provided that the treatment is well tolerated, treated BP values should be targeted to $130 / 80 \mathrm{~mm} \mathrm{Hg}$ or lower in most patients. In patients $<65$ years, SBP should be targeted to $120-129 \mathrm{~mm} \mathrm{Hg}$ in the majority. In patients $>65$ years, it is recommended that SBP should be lowered to a BP range of 130 to $139 \mathrm{~mm} \mathrm{Hg}$ while DBP should be lowered to $<80 \mathrm{~mm} \mathrm{Hg}$ irrespective of age (- Fig. 1 ).

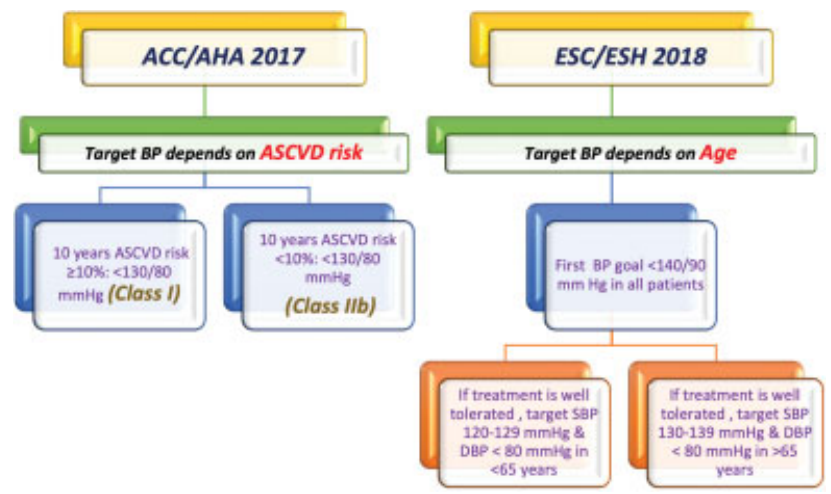

Fig. 1 Variable BP targets according to the two guidelines. ACC/AHA, American College of Cardiology/American Heart Association; ASCVD, atherosclerotic cardiovascular disease; BP, blood pressure; DBP, diastolic blood pressure; ESC/ESH, European Society of Cardiology/European Society of Hypertension; SBP, systolic blood pressure.

\section{Nonpharmacological Interventions Are Important at All Stages}

Both guidelines put emphasis on the importance of nonpharmacological interventions that are the cornerstone of management in early stages of HTN and also have synergistic role in managing HTN along with drug therapy. Nonpharmacological interventions provide modest $(2-10 \mathrm{~mm} \mathrm{Hg}$ reduction) reduction in BP with maximum benefit from dietary modification especially the dietary approaches to stop HTN (DASH) diet. Major interventions with proven long-term benefit include weight loss, DASH diet, increased physical activity, salt restriction, potassium supplementation, and moderation of alcohol.

\section{When to Start Drug Treatment}

The ACC/AHA guidelines recommend initiating antihypertensive drug therapy in Stage 2 HTN along with nonpharmacological maneuvers. For Stage $1 \mathrm{HTN}$, it recommends initiating antihypertensive drug therapy only when there is clinical ASCVD or 10 -year CVD risk exceeds $10 \%$. Of course, nonpharmacological should be initiated along with them too.

The ESC guidelines state that adults with Grade 2 or 3 HTN should receive drug treatment along with lifestyle intervention. For patients with Grade 1 HTN, pharmacotherapy should be offered to patients with presence of HTN-mediated target organ damage, those with renal disease, ASCVD, and those at high or very high CV risk. For low-to-moderate risk patients with Grade 1 hypertension, a trial of lifestyle intervention is advocated before considering drugs.

\section{Special Considerations in Frail and Older Patients}

The ESC guidelines mention that for people over the age of 80 years, who have not yet received treatment for their BP, BP treatment should be considered when office systolic BP is $160 \mathrm{mmHg}$. Frailty, dependency and expectations of treatment benefit will influence the decision to treat people aged $>80$ years, on an individual patient basis, but these patients should not be denied treatment, or have treatment withdrawn simply on the basis of age.

The ACC/AHA guidelines mention that in ambulatory, non-institutionalized adults aged $\geq 65$ years antihypertensive drug therapy should be initiated at $\mathrm{SBP} \geq 130 \mathrm{~mm} \mathrm{Hg}$ and treated to SBP goal $<130 \mathrm{~mm}$ of $\mathrm{Hg}$ (- Fig. 2).

\section{Choice of Antihypertensive}

Thiazide diuretics, calcium channel blockers (CCB), angiotensin-converting enzyme inhibitors (ACE-I), and angiotensin receptor blockers (ARBs) continue to be the frontline drugs for initiation of pharmacotherapy in the ACC/AHA guidelines. All these classes of drug have shown $\mathrm{CV}$ risk reduction when compared with placebo in randomized trials. $^{9,10}$ Beta-blockers continue their relegated status due to a negative impact on central aortic BP and lack of protection from stroke. The overall aim is to achieve sustainable BP reduction for trimming CV risk and choice of individual agent is of less concern. Following initiation of therapy, a monthly follow-up is needed until target BP goals are achieved. 

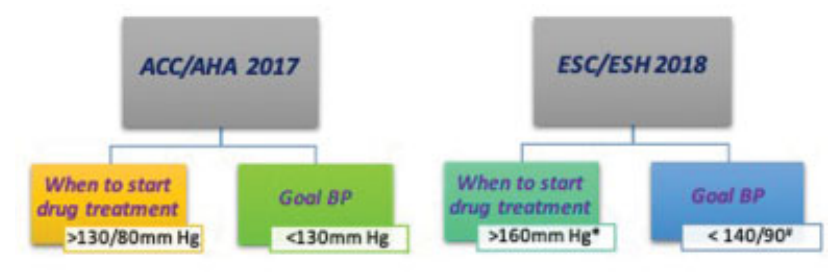

Fig. 2 BP considerations for elderly and frail ("In patients aged $>65$ years but not $>80$ years, drug therapy and lifestyle changes can be initiated when SBP $>140-159 \mathrm{~mm} \mathrm{Hg}$, provided that treatment is well tolerated. \#Can go up to $130 \mathrm{~mm} \mathrm{Hg}$ but not less than that). ACC/AHA, American College of Cardiology/American Heart Association; BP, blood pressure; ESC/ESH, European Society of Cardiology/European Society of Hypertension; SBP, systolic blood pressure.

The ESC guidelines recommend a simplified drug treatment algorithm with combination of an ACE inhibitor or ARB with a CCB or thiazide/thiazide-like diuretic. For those requiring three drugs, a combination of an ACE-inhibitor or ARB with a CCB and a thiazide/ thiazide-like diuretic should be used. Beta-blockers should be used when there is a specific indication for their use, for example, angina, postmyocardial infarction, heart failure with reduced ejection fraction, or when heart rate control is required.

\section{Monotherapy versus Upfront Combination Therapy} The ACC/AHA guidelines recommend initiating monotherapy in Stage 1 HTN and state a BP goal $<130 / 80 \mathrm{~mm} \mathrm{Hg}$. The guidelines recommend upfront initiation of two-drug combination in patients with Stage $2 \mathrm{HTN}$ with BP $>20 / 10 \mathrm{~mm} \mathrm{Hg}$ above their goal. The rationale for such a strategy rests on the facts that majority of the patients would need two or more drug for attaining BP goals and those with every high BP have also high CV risk. Also, it is now proven that combination therapy attains better (up to five times) antihypertensive effect than doubling the dose of a single drug. ${ }^{11,12}$

The ESC guidelines recommend starting treatment in most patients with two drugs. Monotherapy is usually inadequate therapy for most people with HTN and initial therapy with combination of two drugs should be considered usual care for HTN. The only exception would be in a limited number of patients with a lower baseline BP close to their recommended target, who might achieve that target with a single drug, or in some frailer old or very old patients, in whom more gentle reduction of BP may be desirable (-Fig. $\mathbf{3}$ ).

\section{A Single Pill Strategy to Treat Hypertension}

The ESC guidelines state that poor adherence to BP-lowering medication is directly related to the number of pills and is a major factor contributing to poor BP control rates. ${ }^{13,14}$ Single pill combination therapy is now the preferred strategy for initial two-drug combination treatment of HTN and for three-drug combination therapy when required. That the individual agents in such a polypill maintain their anticipated effects have now been demonstated. ${ }^{15}$
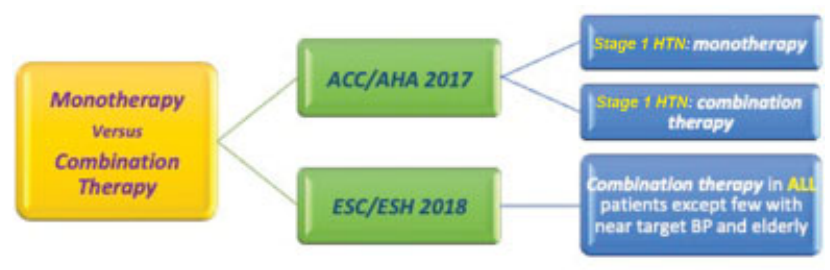

Fig. 3 Monotherapy versus combination therapy in pharmacological management of hypertension. ACC/AHA, American College of Cardiology/American Heart Association; BP, blood pressure; ESC/ESH, European Society of Cardiology/European Society of Hypertension; HTN, hypertension.

The ACC/AHA guidelines also recommend fixed-dose combination as they have revealed better compliance and greater BP lowering.

\section{BP Threshold and Goal for Adults with DM}

The ACC/AHA guidelines mention that in adults with diabetes mellitus (DM) and HTN, antihypertensive drug therapy to be initiated at $\mathrm{SBP} \geq 130 \mathrm{~mm} \mathrm{Hg}$ or $\mathrm{DBP} \geq 80 \mathrm{~mm} \mathrm{Hg}$ and treat to goal of $<130 / 80$.

The ESC guidelines do not mention a separate recommendation for DM patients.

\section{BP Threshold and Goal for Adults with CKD}

The ACC/AHA guidelines recommend that in adults with chronic kidney disease (CKD) and HTN, antihypertensive drug therapy to be initiated at SBP $\geq 130 \mathrm{~mm} \mathrm{Hg}$ or DBP $\geq 80 \mathrm{~mm} \mathrm{Hg}$ and treat to goal of $\mathrm{SBP}<130 \mathrm{~mm} \mathrm{Hg}$ and $\mathrm{DBP}<80 \mathrm{~mm} \mathrm{Hg}$.

The ESC guidelines do not mention a separate recommendation for CKD patients.

\section{Resistant HTN}

The ESC guidelines recommended treatment of resistant HTN by addition of low-dose spironolactone to existing treatment. If the patient is intolerant to spironolatone, other options include-eplerenone, amiloride, higher-dose thiazide/thiazide-like diuretic, loop diuretic, bisoprolol and doxazosin.

The ACC/AHA guidelines similarly recommend maximizing diuretic therapy (i.e., substitute chlorthalidone or indapamide for hydrochlorothiazide) or adding an MRA.

\section{Detecting Poor Adherence to Drug Therapy}

The ESC guidelines have put a strong emphasis on the importance of evaluating treatment adherence as a major cause of poor BP control.

No such emphasis has been made in the ACC/AHA guidelines.

\section{A Key Role for Nurses and Pharmacists in the Longer- Term Management of Hypertension}

The ESC guidelines mention the important role of nurses and pharmacists in the education, support, and follow-up of treated hypertensive patients is emphasized as part of the overall strategy to improve BP control. 
Table 3 Salient comparison of ACC/AHA 2017 and ESC/ESH 2018 guidelines

\begin{tabular}{|c|c|c|c|c|c|c|c|}
\hline & & \multicolumn{3}{|c|}{ ACC/AHA 2017} & \multicolumn{3}{|c|}{ ESC/ESH 2018} \\
\hline 1. & Defining normal BP & \multicolumn{3}{|c|}{$<120 / 80 \mathrm{~mm} \mathrm{Hg}$} & \multicolumn{3}{|c|}{$\begin{array}{l}\text { SBP: } 120-129 \mathrm{~mm} \mathrm{Hg} \\
\text { DBP: } 80-84 \mathrm{mmHg} \\
<120 / 80 \mathrm{~mm} \mathrm{Hg} \text { is "Optimal" }\end{array}$} \\
\hline 2. & Newer terminology before labeling patient as hypertensive & \multicolumn{3}{|c|}{$\begin{array}{l}\text { "Elevated BP" } \\
\text { SBP: } 120-129 \mathrm{mmHg} \\
\text { DBP: }<80 \mathrm{~mm} \mathrm{Hg}\end{array}$} & \multicolumn{3}{|c|}{$\begin{array}{l}\text { "High normal” } \\
\text { SBP: } 130-139 \mathrm{~mm} \mathrm{Hg} \\
\text { DBP: } 85-89 \mathrm{~mm} \mathrm{Hg}\end{array}$} \\
\hline \multirow[t]{4}{*}{3.} & \multirow[t]{4}{*}{ Classification of HTN } & & SBP & DBP & & SBP & DBP \\
\hline & & Stage 1 & $130-139$ & $80-89$ & Grade 1 & $140-159$ & $90-99$ \\
\hline & & \multirow[t]{2}{*}{ Stage 2} & \multirow[t]{2}{*}{$>140$} & \multirow[t]{2}{*}{$>90$} & Grade 2 & $160-179$ & $100-109$ \\
\hline & & & & & Grade 3 & $>180$ & $>110$ \\
\hline 4. & Separate classification of isolated systolic HTN & \multicolumn{3}{|l|}{-} & \multicolumn{3}{|c|}{$\begin{array}{l}\mathrm{SBP}>140 \mathrm{~mm} \mathrm{Hg} \\
\mathrm{DBP}<90 \mathrm{~mm} \mathrm{Hg}\end{array}$} \\
\hline 5. & Screening programs for HTN & \multicolumn{3}{|l|}{-} & \multicolumn{3}{|c|}{ Special emphasis given } \\
\hline 6. & Accurate BP recording & \multicolumn{3}{|c|}{$\begin{array}{l}\text { Special emphasis given to- } \\
\text { - Taking multiple readings } \\
\text { - Average of multiple } \\
\text { recordings }\end{array}$} & \multicolumn{3}{|l|}{-} \\
\hline 7. & CVD risk assessment & \multicolumn{3}{|c|}{$\begin{array}{l}\text { - } 10 \text { year ASCVD risk score } \\
\text { implemented. } \\
\text { - Intensive HTN therapy is } \\
\text { recommended if risk }>10 \%\end{array}$} & \multicolumn{3}{|c|}{$\begin{array}{l}\text { SCORE system implemented but } \\
\text { intensification of HTN treatment } \\
\text { depending on risk score is not } \\
\text { mentioned }\end{array}$} \\
\hline 8. & Statin as primary prophylaxis & \multicolumn{3}{|c|}{ No such mention } & \multicolumn{3}{|c|}{$\begin{array}{l}\text { Recommended in established } \\
\text { CVD or moderate-to-high CVD } \\
\text { risk according to SCORE system }\end{array}$} \\
\hline 9. & Low-dose aspirin & \multicolumn{3}{|c|}{ No such mention } & \multicolumn{3}{|c|}{ As secondary prophylaxis } \\
\hline 10. & BP target & \multicolumn{3}{|c|}{$\begin{array}{l}\text { Target BP depend on } \\
\text { ASCVD risk } \\
-10 \text { year ASCVD risk } \\
\geq 10 \%:<130 / 80 \mathrm{~mm} \mathrm{Hg} \\
\text { (Class I) } \\
\quad 10 \text { year ASCVD risk } \\
\quad<10 \%:<130 / 80 \mathrm{~mm} \mathrm{Hg} \\
\quad \text { (Class Ilb) } \\
\end{array}$} & \multicolumn{3}{|c|}{$\begin{array}{l}\text { Target BP depend on age } \\
- \text { BP }<140 / 90 \mathrm{~mm} \mathrm{Hg} \text { in all } \\
\text { patients, if treatment is well } \\
\text { tolerated, then target to } \\
130 / 80 \\
\text { - SBP } 120-129 \mathrm{~mm} \mathrm{Hg} \text { in }<65 \\
\text { years age }\end{array}$} \\
\hline 11. & When to start drug treatment & \multicolumn{3}{|c|}{$\begin{array}{l}\text { In stage } 2 \text { HTN } \\
\text { In stage } 1 \text { HTN with ASCVD } \\
\text { risk }>10 \%\end{array}$} & \multicolumn{3}{|c|}{$\begin{array}{l}\text { HTN }>\text { Grade } 2 \\
\text { Start in Grade } 1 \text { with High CV } \\
\text { risk and evidence of target or- } \\
\text { gan damage }\end{array}$} \\
\hline \multirow[t]{2}{*}{12.} & $\begin{array}{l}\text { Special consideration for old and frail } \\
\text { - When to start drug treatment }\end{array}$ & \multicolumn{3}{|c|}{$\mathrm{BP}>130 / 80 \mathrm{~mm} \mathrm{Hg}$} & \multicolumn{3}{|c|}{$\mathrm{SBP}>160 \mathrm{~mm} \mathrm{Hg}$} \\
\hline & - Goal BP & \multicolumn{3}{|c|}{$\mathrm{SBP}<130 \mathrm{~mm} \mathrm{Hg}$} & \multicolumn{3}{|c|}{ SBP: $130-139 \mathrm{~mm} \mathrm{Hg}$} \\
\hline 13. & DM & \multicolumn{3}{|c|}{ Target is $<130 / 80$} & \multicolumn{3}{|c|}{ No separate recommendation } \\
\hline 14. & CKD & Target is & $<130 / 80$ & & No separ & te recomm & endation \\
\hline 15. & Combination therapy & $\begin{array}{l}\text { Stage 1: } \\
\text { Stage 2: }\end{array}$ & $\begin{array}{l}\text { monothera } \\
\text { combinatio }\end{array}$ & & $\begin{array}{l}\text { Combina } \\
\text { patients } \\
\text { target BF }\end{array}$ & $\begin{array}{l}\text { ion therapy } \\
\text { except few } \\
\text { and elderly }\end{array}$ & $\begin{array}{l}\text { in all } \\
\text { fith near }\end{array}$ \\
\hline 16. & Emphasis on adherence to drug therapy & - & & & Emphasi & & \\
\hline 17. & Role of paramedical staff in long-term management of HTN & - & & & Emphasi & & \\
\hline
\end{tabular}

Abbreviations: ACC/AHA, American College of Cardiology/American Heart Association; ASCVD, atherosclerotic CVD; CKD, chronic kidney disease; DBP, diastolic blood pressure; DM, diabetes mellitus; ESC/ESH, European Society of Cardiology/European Society of Hypertension; HTN, hypertension; SBP, systolic blood pressure.

No such mention has been made in the ACC/AHA guidelines.

\section{Conclusion}

HTN guidelines are intended to guide clinicians on key issues of primary prevention of HTN by lifestyle modifications as well as secondary prevention by timely diagnosing and treating it. These guidelines help to clear the confusing issues like BP targets and optimal way to achieve these targets. Despite the differences in recommendations of various HTN guidelines over the years, all guidelines converge over the universal belief that HTN is the single most important treatable cardiovascular risk factor. - Table 3 summarizes 


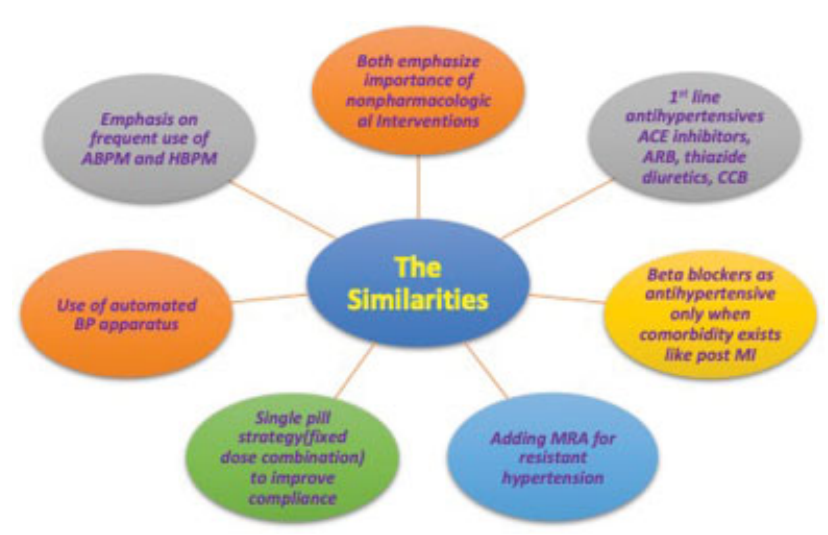

Fig. 4 Features common to both the guidelines. ABPM, ambulatory blood pressure monitoring; ARB, angiotensin receptor blocker; ACE, angiotensin-converting enzyme inhibitor; $C C B$, calcium channel blocker; HBPM, home blood pressure monitoring; MI, myocardial infarction; MRA, mineralocorticoid receptor antagonist.

the important differences among two of the most widely accepted guidelines over the world. - Fig. 4 summarizes the common aspects of both the guidelines.

\section{Conflict of Interest}

The authors have none to declare.

\section{Acknowledgment of Grant Support}

Nil.

\section{References}

1 Chobanian AV, Bakris GL, Black HR, et al; National Heart, Lung, and Blood Institute Joint National Committee on Prevention, Detection, Evaluation, and Treatment of High Blood Pressure National High Blood Pressure Education Program Coordinating Committee. The Seventh Report of the Joint National Committee on Prevention, Detection, Evaluation, and Treatment of High Blood Pressure: the JNC 7 report. JAMA 2003;289(19):2560-2572

2 Mills KT, Bundy JD, Kelly TN, et al. Global disparities of hypertension prevalence and control: a systematic analysis of population-based studies from 90 countries. Circulation 2016;134(06):441-450

3 Whelton PK, Carey RM, Aronow WS, et al. 2017 ACC/AHA/AAPA/ ABC/ACPM/AGS/APhA/ASH/ASPC/NMA/PCNA guideline for the prevention, detection, evaluation, and management of high blood pressure in adults: A Report of the American College of Cardiology/American
Heart Association task force on clinical practice guidelines. J Am Coll Cardiol 2018;71(19):e127-e248

4 Williams B, Mancia G, Spiering W, et al; ESC Scientific Document Group. 2018 ESC/ESH Guidelines for the management of arterial hypertension. Eur Heart J 2018;39(33):3021-3104

5 Williams B, Mancia G. Ten commandments of the 2018 ESC/ESH HTN guidelines on hypertension in adults. Eur Heart J 2018;39 (33):3007-3008

6 Pradhan A, Vishwakarma P. Decoding the 2017 hypertension guidelines: the ten commandments. Heart India 2017; 5:139-144

7 American College of Cardiology. ASCVD Risk Predictor Plus. Accessed on May 5, 2021 at: http://tools.acc.org/ASCVD-RiskEstimator-Plus/\#!/calculate/estimate/

8 Piepoli MF, Hoes AW, Agewall S, et al; ESC Scientific Document Group. 2016 European Guidelines on cardiovascular disease prevention in clinical practice: The Sixth Joint Task Force of the European Society of Cardiology and Other Societies on Cardiovascular Disease Prevention in Clinical Practice (constituted by representatives of 10 societies and by invited experts) Developed with the special contribution of the European Association for Cardiovascular Prevention \& Rehabilitation (EACPR). Eur Heart J 2016;37(29):2315-2381

9 Thomopoulos C, Parati G, Zanchetti A. Effects of blood pressurelowering on outcome incidence in hypertension: 5. Head-tohead comparisons of various classes of antihypertensive drugs overview and meta-analyses. J Hypertens 2015;33(07): 1321-1341

10 Ettehad D, Emdin CA, Kiran A, et al. Blood pressure lowering for prevention of cardiovascular disease and death: a systematic review and meta-analysis. Lancet 2016;387(10022):957-967

11 Law MR, Wald NJ, Morris JK, Jordan RE. Value of low dose combination treatment with blood pressure lowering drugs: analysis of 354 randomised trials. BMJ 2003;326(7404):1427

12 Wald DS, Law M, Morris JK, Bestwick JP, Wald NJ. Combination therapy versus monotherapy in reducing blood pressure: metaanalysis on 11,000 participants from 42 trials. Am J Med 2009;122 (03):290-300

13 Corrao G, Parodi A, Zambon A, et al. Reduced discontinuation of antihypertensive treatment by two-drug combination as first step. Evidence from daily life practice. J Hypertens 2010;28 (07):1584-1590

14 Gupta AK, Arshad S, Poulter NR. Compliance, safety, and effectiveness of fixed-dose combinations of antihypertensive agents: a meta-analysis. Hypertension 2010;55(02):399-407

15 Coca A, Agabiti-Rosei E, Cifkova R, Manolis AJ, Redón J, Mancia G. The polypill in cardiovascular prevention: evidence, limitations and perspective - position paper of the European Society of Hypertension. J Hypertens 2017;35(08):1546-1553 